\title{
ISSUES IN CHILD HEALTH \\ Can a new paediatric sub-specialty improve child health in South Africa?
}

\author{
George Swingler, Michael Hendricks, David Hall, Susan Hall, David Sanders, Neil McKerrow, Haroon Saloojee, Steve Reid
}

Compared with other middle-income countries, child health in South Africa is in a poor state, and should be addressed by focusing on the healthcare needs of all children across a system or region. Paediatricians have had little effect on this situation, partly because their training is not aligned with South African needs. The proposed re-engineering of primary healthcare will be limited by the skewed distribution of staff and the lack of suitable skills. A 'community' placement during specialist training, and the creation of a sub-specialty in Community Paediatrics and Child Health, could address the skills shortage and possibly attract health personnel to under-served areas through creating an appropriate career path. This proposal would also support the Department of Health's encouraging plans to re-engineer primary healthcare.

S Afr Med J 2012;102(9):738-739. DOI:10.7196/SAMJ.5714
South Africa's grim child health statistics have deteriorated, with under-5 mortality rising from 56 per 1000 live births in 1990, to 67 in $2008^{1}$ and just over half of all under- 5 deaths occurring outside health facilities. ${ }^{2}$ In contrast, during the same period, under-5 mortality has fallen by more than $60 \%$ in other middle-income countries such as Brazil and Mexico. Beyond mortality, we know little about care of chronic disease (other than infections) in children, management of disabled children (including epilepsy), child abuse, adolescent problems, or transition from children's to adult services in South Africa. Those reaching the health services often represent only the tip of the iceberg of childhood morbidity. All but invisible are problems of children and young people, ${ }^{3}$ such as sexual and physical violence, mental health problems, and adolescent pregnancy, drugs, crime and suicide. The country's political and economic history underlies much of this ill-health. ${ }^{4}$ South Africa is among the world's most unequal societies, with a Gini coefficient of 0.666 in 2008.

In the health sector, human resource numbers and skills have not grown in proportion with the population or increasing burden of disease. Between 1997 and 2006, the number of specialists in the public sector declined by $25 \%$ while non-specialist medical practitioners increased by only $8.4 \% .^{5}$ The shortage of doctors is aggravated by maldistribution between private and public sectors and urban and rural areas, and public sector doctors concentrated in large city hospitals are often not easily accessible to residents of townships and informal settlements.

South African medical graduates are out of step with South Africa's

George Swingler and Michael Hendricks are general paediatricians, and David Hall and Susan Hall Honorary Professors of Paediatrics, at the University of Cape Town. David Sanders is a paediatrician and Emeritus Professor of Public Health at the University of the Western Cape. Neil McKerrow is Chief Specialist and Head of Paediatrics \& Child Health at the Pietermaritzburg Metropolitan Hospital Complex. Haroon Saloojee heads the Division of Community Paediatrics at the University of the Witwatersrand, and Steve Reid is Director of the Primary Health Care Directorate at UCT. health needs. A review of South African health sciences faculties found that students spent only 3 - 25\% of clinical curriculum time in community or rural settings, that rural supervision was inadequate, and that there was no formal assessment of clinical practice in rural or under-served areas. ${ }^{6}$ General paediatricians and sub-specialists are skilled in managing specialised clinical problems, but usually pay little attention to the prevention and primary management of these conditions, as most of their training is in tertiary hospitals.

\section{An opportunity ... and towards a solution}

Consequently, it is not surprising that paediatricians have had little impact on child health outcomes. However, the Minister of Health has announced exciting plans for re-engineering primary healthcare, seen as a critical component of the National Health Insurance (NHI). ${ }^{7}$ As part of this drive, district clinical specialist teams each including a paediatrician, based in all health districts, will complement existing services, shifting the emphasis from individual patient care to community care. Hospitals will take responsibility for individuals seeking care in their facilities and for their catchment populations. Outreach activities will continue, and be expanded, by facility-based specialists while district teams will create an appropriate environment for effective care.

This re-engineering requires better distribution of relevant human resources, including paediatricians appropriately trained in general paediatrics and child public health. Ironically, the community aspects of child health receive more attention in some highly resourced countries where under- 5 mortality rates are 10 times lower. The American Academy of Pediatrics has a policy statement ${ }^{8}$ that defines community paediatrics, including 'A perspective that enlarges the pediatrician's focus from one child to all children in the community' and is 'An integral part of the professional role and duty of the pediatrician'. The UK is committed to meeting the health needs of children through the practice of Community Child Health $(\mathrm{CCH})$, which is a registered sub-specialty.?

South African graduates and paediatricians need better knowledge and experience of clinical conditions and contexts outside highly specialised hospitals. Paediatric specialist training should include compulsory registrar placements for at least 6 months at regional hospitals, including supporting child health services in surrounding district hospitals and primary care facilities. Sufficient appropriately functioning units and suitably trained paediatric specialists and subspecialists are essential for improved services. 


\section{A new paediatric sub-specialty}

In response to this disturbing situation and the opportunity created by the re-engineering plans, a new sub-specialty has been accredited in paediatrics, which should focus on the healthcare needs of all children across a system or region, with district health services supported by integrated and mutually supportive referral systems with general specialist (regional) and tertiary hospitals. Although the nature of the work will vary with the local context, generic roles and responsibilities of this sub-specialty include:

- promoting the health of children at a community level

- raising the quality of care for children in all primary and secondary healthcare facilities

- co-ordinating relevant education and training of health professionals at these levels

- participation, to a limited extent, in delivering clinical care in the regional/referral hospital

- collaboration in establishing and maintaining systems for surveillance, health information, communication and referral

- overall leadership, advice and advocacy for children's services in a geographical area including key child health and nutrition programmes.

Naming the sub-specialty 'Community Paediatrics and Child Health' bridges the gaps between individual and collective care, and between clinical and public healthcare for children.

The former functions could be performed by clinicians other than sub-specialists, and are applicable to many general paediatricians and medical officers who, as clinicians, already take responsibility for health service co-ordination and delivery in a geographically defined community. Creating a sub-specialty to promote a broad clinical approach to child health appears paradoxical; the danger is that community-wide child health may be seen as the responsibility of a small group of sub-specialists, rather than as part of every paediatrician's responsibility. However, we expect particular benefits from someone with the proposed training and competencies working alongside and supporting less specialised doctors: positive health practices and strengthened home and community health services; increased skills and a redistribution of staff; improved support of junior medical staff throughout the District Health System; more appropriate training platforms for under- and postgraduates; a foundation for relevant research and a strengthened knowledge base in community child health; and an integration of clinical practice and population health that is largely missing from South African healthcare.

\section{Towards implementation}

Training would incorporate acquiring knowledge and the vocational application of the knowledge and skills. Sub-specialist candidates, after paediatric specialisation, would complete two years of vocational training at an accredited site and obtain a CMSA Certificate and registration with the HPCSA. For this training, additional senior registrar (sub-specialist) posts are needed in appropriate settings. Interested general doctors or specialists who do not sub-specialise should also obtain a formal qualification such as a Postgraduate Diploma or Master's qualification. Distance or mixed-mode training would allow learning while working on the job at a relevant site under the supervision of a sub-specialist paediatrician in Community Paediatrics and Child Health.

Experience in Western Australia, ${ }^{9}$ Canada and the highlands and islands of Scotland suggests that the success and sustainability of such initiatives depends in part on addressing the obstacles to implementation, including concerns about lifestyle and security. Therefore, investment will be needed in peri-urban and rural infrastructure, including health facilities, and financial and nonfinancial incentives.

\section{Why only paediatrics?}

The above principles may also be applicable to other specialists and to clinicians without formal specialisation. Generic factors across disciplines and levels of clinical specialisation (including a core curriculum, appropriate training platforms, and career paths) could provide opportunities for collaboration between disciplines and universities to develop training and to advocate recognition of this group of clinicians.

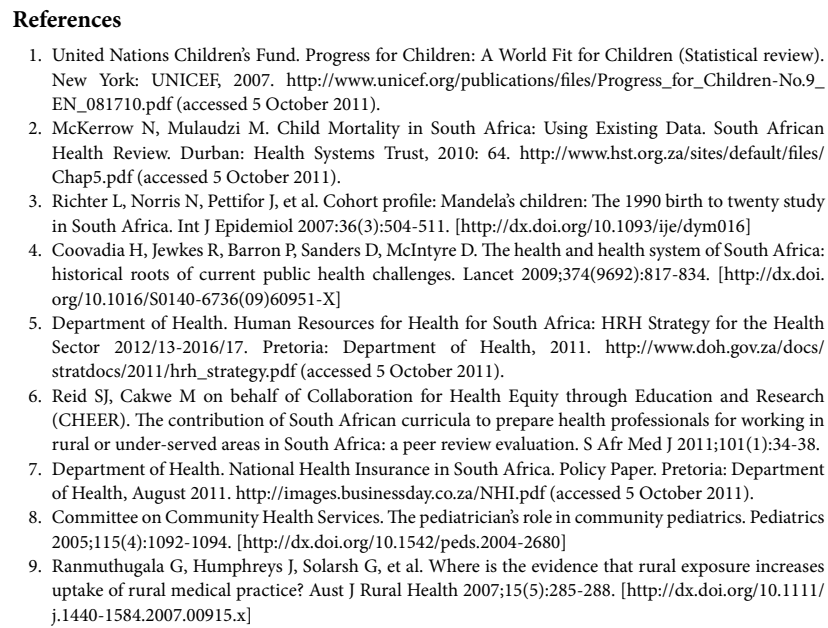

1. United Nations Children's Fund. Progress for Children: A World Fit for Children (Statistical review) New York: UNICEF, 2007. http://www.unicef.org/publications/files/Progress_for_Children-No.9 EN_081710.pdf (accessed 5 October 2011).

2. McKerrow N, Mulaudzi M. Child Mortality in South Africa: Using Existing Data. South African Health Review. Durban: Health Systems Trust, 2010: 64. http://www.hst.org.za/sites/default/files/ Chap5.pdf (accessed 5 October 2011).

3. Richter L, Norris N, Pettifor J, et al. Cohort profile: Mandela’s children: The 1990 birth to twenty study in South Africa. Int J Epidemiol 2007:36(3):504-511. [http://dx.doi.org/10.1093/ije/dym016]

4. Coovadia H, Jewkes R, Barron P, Sanders D, McIntyre D. The health and health system of South Africa: Coovadia $\mathrm{H}$, Jewkes R, Barron P, Sanders D, McIntyre D. The health and health system of South Africa:
historical roots of current public health challenges. Lancet 2009;374(9692):817-834. [http://dx.doi. org/10.1016/S0140-6736(09)60951-X]

5. Department of Health. Human Resources for Health for South Africa: HRH Strategy for the Health Sector 2012/13-2016/17. Pretoria: Department of Health, 2011. http://www.doh.gov.za/docs stratdocs/2011/hrh_strategy.pdf (accessed 5 October 2011).

6. Reid SJ, Cakwe M on behalf of Collaboration for Health Equity through Education and Research (CHEER). The contribution of South African curricula to prepare health professionals for working in rural or under-served areas in South Africa: a peer review evaluation. S Afr Med J 2011;101(1):34-38.

7. Department of Health. National Health Insurance in South Africa. Policy Paper. Pretoria: Department of Health, August 2011. http://images.businessday.co.za/NHI.pdf (accessed 5 October 2011).

8. Committee on Community Health Services. The pediatrician's role in community pediatrics. Pediatrics 2005;115(4):1092-1094. [http://dx.doi.org/10.1542/peds.2004-2680]

9. Ranmuthugala G, Humphreys J, Solarsh G, et al. Where is the evidence that rural exposure increases uptake of rural medical practice? Aust J Rural Health 2007;15(5):285-288. [http://dx.doi.org/10.1111/
und j.1440-1584.2007.00915.x]

Accepted 29 February 2012 